\title{
Origin of the $\alpha$-Effect in Nucleophilic Substitution Reactions of Y-Substituted Phenyl Benzoates with Butane-2,3-dione Monoximate and Z-Substituted Phenoxides: Ground-State Destabilization vs. Transition-State Stabilization
}

\author{
Mi Sun Kim, Se-Won Min, Jin-A Seo, and Ik-Hwan Um \\ Deparment of Chemistry and Nano Science, Enha Womans Lniversity, Seoul 120-750, Korea. E-mail: ihwmatewhack \\ Recerved September 22, 2009, Accepted October 23, 2009
}

\begin{abstract}
Second-order rate constants ( $k_{\mathrm{Nin}}$ ) have been measured for nucleophilic substitution reactions of $Y$-substituted phenyl benzoates ( $1 \mathrm{a}-\mathrm{i})$ with butane-2,3-dione monoximate ( $\mathrm{Ox}^{-}$, an $\alpha$-nkeleophile) and Z-substituted phenoxides in $80 \mathrm{~mol} \%$ $\mathrm{H}_{2} \mathrm{O} / 20 \mathrm{~mol} \% \mathrm{DMSO}$ at $25.0 \pm 0.1^{\circ} \mathrm{C}$. Hammett plots correlated with $\sigma^{\circ}$ and $\sigma^{-}$constants for reactions of la-h with $\mathrm{Ox}^{-}$ exhibit many scattered points. In contrast, the Yukawa-Tsuno plot results in a good linear correlation with $\rho_{Y}=2.20$ and $r=0.45$, indicating that expulsion of the leaving group occurs in the rate-determining step (RDS). A stepwise mechanism with expulsion of the leaving-group being the RDS has been excluded, since Y-substituted phenoxides are less basic and better nucleofuges than $\mathrm{Ox}^{-}$. Thus, the reactions have been concluded to proceed through a concerted mechanism. $\mathrm{Ox}^{-}$ is over $10^{2}$ times more reactive than its reference nucleophile, 4-chlorophenoxide (4-ClPhO). One might suggest that stabilization of the transition-state (TS) through intramolecular general acid/base cataly'sis is responsible for the $\alpha$-effect since such general acid/base cataly sis is not possible for the corresponding reactions with 4-CIPhO'- However, destabilization of the ground-state (GS) of $\mathrm{Ox}^{-}$has been concluded to be mainly responsible for the a-effect found in this study on the basis of the fact that the magnitude of the $\alpha$-effect is independent of the nature of the substituent $Y$.
\end{abstract}

Key Words: The $\alpha$-effect, Concerted mechanism. Ground-state destabilization. Solvent effect. Transition-state stabilization

\section{Intmoduction}

Nucleophiles possessing one or more nonbonding electron pairs on the atom $\alpha$ to the nucleophilic site have often been reported to exhibit abnormally enhanced reactivity than would be expected from their basicity. ${ }^{1-19}$ Thus. the enhanced reactivity shown by these nucleophiles was termed the $\alpha$-effect. ' Numerous studies have been performed to investigate the cause of the $\alpha$-effect. ${ }^{3-19}$ Many theories have been advanced to explain the $\alpha$ effect. e.g.. destabilization of the ground state (GS) due to electronic repulsion between the nonbonding electron pairs, transition state (TS) stabilization including general acid/base cataly sis. thermodynamic stability of products. solvent effects. ${ }^{2-19}$ However. none of these theories is conclusive. Particularly. solvent effect on the $\alpha$-effect remains controversial. ${ }^{8-19}$

Solvent effect was suggested to be unimportant since the magnitude of the $\alpha$-effects was found to be similar for reactions performed in $\mathrm{H}_{2} \mathrm{O}$ and in organic solvents such as MeCN and toluene ${ }^{8}$ Besides, it has been reported that $\alpha$-nucleophiles are intrinsically more reactive than normal micleophiles of similar basicity in gas-phase reactions. ${ }^{3.11}$ High-level theoretical calculations have also shown that $\alpha$-nucleophiles (e.g. $\mathrm{HOO}^{-}$. $\mathrm{H}_{2} \mathrm{NO}^{-} . \mathrm{FO}^{-}$and $\mathrm{ClO}^{-}$) exhibit lower activation energies than normal nucleophiles of similar basicity in gas-phase $\mathrm{S}_{\mathrm{N}} 2$ reactions. "Accordingly. solvent effect on the $a$-effect has been concluded to be unimportant. ${ }^{8-1]}$ In contrast, DePuy et al. concluded that solvent effect is responsible for the $\alpha$-effect shown by $\mathrm{HOO}^{-}$in $\mathrm{H}_{2} \mathrm{O}$. since the $\alpha$-nucleoplile did not exhibit the $\alpha$ effect in the gas-phase reaction with methyl formate. ${ }^{12}$ Furthermore, from recent gas-phase ion-molecule studies, Bierbaum et $a l$. have found that $\alpha$-nucleophiles such as $\mathrm{HOO}^{-} . \mathrm{BrO}^{-}$and $\mathrm{ClO}^{-}$do not exhibit enhanced reactivity in gas-phase reactions with alkyl chlorides. ${ }^{13}$ Accordingly, they have concluded that the $\alpha$-effect is due to solvent effect but not due to an intrinsic property. 12.13

We have initiated a systematic study to investigate the effect of solvent on the $\alpha$-effect. ${ }^{1+1}$ Our study has shown that solvent effect on the $\alpha$-effect is rentarkable for nucleoplilic substitution reactions of 4-nitrophenyl acetate (PNPA) with butane-2.3dione monoximate $\left(\mathrm{Ox}^{-}\right.$, an $\alpha$-nucleophile) and 4-chlorophenoxide (4-ClPhO- , a reference nucleophile) in DMSO- $\mathrm{H}_{2} \mathrm{O}$ mixtures of varying compositions. ${ }^{\text {th }}$ It has been found that the $\alpha$-effect (i.e., $\left.k_{1}-k_{4}-c_{10}\right)$ increases as the DMSO content in the medium increases up to $c a .50 \mathrm{~mol} \% \mathrm{DMSO}$ and then decreases thereafter. resulting in a bell-shaped $\alpha$-effect profile. ${ }^{1+}$ Sinilar bell-shaped $\alpha$-effect profiles have been obtained for the corresponding reactions of aryl acetates. 4-nitrophenyl benzoate, thionobenzoate. benzenesulfonate and diphenylphosphinate. although the magnitude of the $\alpha$-effect is highly dependent on the nature of the electrophilic center. ${ }^{15-19}$

Our calorimetric study has revealed that $\mathrm{Ox}^{-}$is $c a+4 \mathrm{kcal} / \mathrm{mol}$ less solvated than $4-\mathrm{ClPhO}^{-}$in $\mathrm{H}_{2} \mathrm{O}^{14(5)}$ Furthermore it has been found that $\mathrm{Ox}^{-}$becomes more destabilized than $4-\mathrm{ClPhO}^{-}$as the DMSO content in the medium increases up to $\mathrm{ca} .50 \mathrm{~mol} \%$ DMSO. and then the difference in their solvation energies remains nearly constant upon further addition of DMSO. ${ }^{\text {th }}$ Dissection of the $\alpha$-effect found in the reactions of PNPA into TS and GS contributions through combination of the kinetic data with calorimetric data has led us to conclude that destabilization of the $\alpha$-nucleoplile (i.e., $\mathrm{Ox}^{-}$) is mainly responsible for the increasing $\alpha$-effect up to $50 \mathrm{~mol} \%$ DMSO (i.e.. GS effect) while differential stabilization of TS contributes to the decreasing $\alpha$-effect beyond 50 mol\% DMSO. ${ }^{\text {lth }}$

Our study has been extended to reactions of Y-substituted 


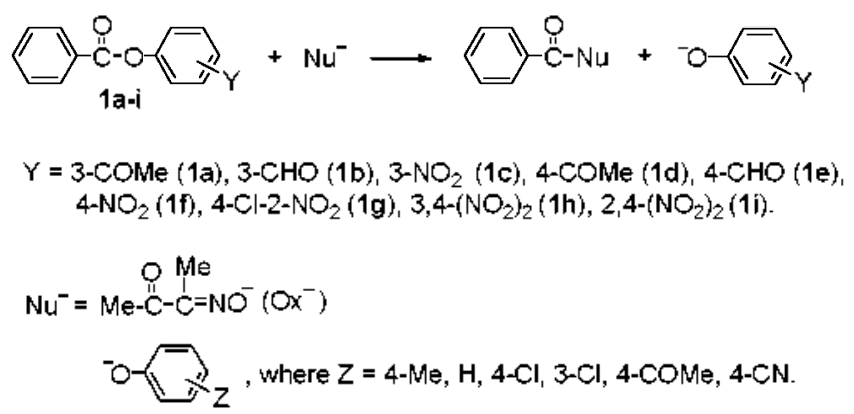

Scheme 1

phenyl benzoates (1a-i) with $\mathrm{Ox}^{-}$and $Z$-substituted phenoxides (Scheme 1) to investigate the origin of the $\alpha$-effect. Comparison of the results obtained in the current study with those reported previously for the corresponding reactions with hydrazine and gly'cylgly cine has shown that destabilization of $\mathrm{Ox}^{-}$is more important than stabilization of TS for the $\alpha$-effect in the current ș̣istem.

\section{Results and Discussion}

Reactions were performed under pseudo-first-order conditions with the concentration of nucleophile in excess over the substrate concentration. All reactions obeyed first-order kinetics with quantitative liberation of $\mathrm{Y}$-substituted phenoxide ion. Pseudo-first-order rate constants ( $\left.k_{\text {otsod }}\right)$ were calculated from the equation $\ln \left(A_{2}-A_{t}\right)=-k_{\text {cosd }} t+C$. The plots of $k_{\text {blbsd }} v s$. nucleoplile concentration were linear with positive intercepts. Thus. the rate law is given as eq ( 1 ). in which $k_{0}$ represents the contribution of $\mathrm{H}_{z} \mathrm{O}$ and $/ \mathrm{or} \mathrm{OH}^{-}$from hydrolysis of the anionic nucleophiles to the $k_{\text {obsd }}$ values. Accordingly. second-order rate constants $\left(k_{\mathrm{Nul}}\right)$ were determined from the slope of the linear plots and summarized in Tables 1 and 2. It is estimated from replicate runs that the uncertainty in the rate constants is less than $\pm 3 \%$.

Rate $=k_{\text {olsd }}$ [substrate]. where $k_{\text {otsil }}=k_{\text {in }}[$ [nucleophile $]+k_{0}$

Reaction Mechanism. As shown in Table 1. second-order rate constant for reactions with $\mathrm{Ox}^{-}$. an $\alpha$-nucleophile, increases as the leaving-group basicity decreases, e.g.. $k \mathrm{cx}^{-}$increases from $0.703 \mathrm{M}^{-1} \mathrm{~s}^{-1}$ to 34.2 and $96 \mathrm{I} \mathrm{M}^{-1} \mathrm{~s}^{-1}$ as the $\mathrm{p} K_{a}$ of the conjugate acid of the leaving group decreases from 10.4 to 7.79 and 5.60 . in turn. A sinuilar result is shown for the corresponding reactions with 4-ClPhO${ }^{-}$(a reference nucleophile). although it is much less reactive than $\mathrm{Ox}^{-}$. The $\alpha$-effect shown by $\mathrm{Ox}^{-}$will be discussed in the following section.

One might expect that a partial negative charge develops on the oxygen atom of the leaving aryloxide when expulsion of the leaving group occurs either in a concerted or stepwise mechanism. Such negative charge can be delocalized on the substituent $Y$ through resonance interactions. Thus. $\sigma^{-}$constants would exhibit a good Hammett correlation if expulsion of the leaving group occurs at rate-deternining step (RDS). In contrast. $\sigma^{\prime \prime}$ constants would result in a better Hammett correlation than $\sigma^{-}$constants if expulsion of the leaving group occurs after RDS. Thus. Hanmett plots have been constructed for reactions of Y-substituted phenyl benzoates (1a-h) with $\mathrm{Ox}^{-}$using $\sigma^{-}$ and $\sigma^{\circ}$ constants to deduce the reaction mechanism. As shown in Figure 1. the Haummett plot correlated with $\sigma^{-}$constants exhibits a slightly better correlation coefficient than that correlated with $\sigma^{\circ}$ constants (inset). However. both Hanmett plots show many scattered points. Accordingly. one cannot get any conclusive information from these plots.

Yukawa-Tsuno plots have been reported to be highly informative to clarify ambiguities in reaction mechanism for nucleophilic substitution reactions of various esters (e.g., aryl benzoates. thionobenzoates. and diphenylphosphinates). ${ }^{21-x_{3}}$ Thus. a Yukawa-Tsuno plot has been constructed for reactions of $\mathbf{1 a - h}$ with $\mathrm{Ox}^{-}$in Figure 2. One can see that the Yukawa-Tsuno plots exhibit a good linear correlation with $\rho_{\mathrm{Y}}=2.20$ and $r=0.45$. The $r$ value in the Yukawa-Tsuno equation (eq 2) represents the extent of resonance contribution between the reaction site and substituent $Y^{24.55}$ Thus. the $r$ value of 0.45 indicates that a negative charge develops partially on the oxygen atom of the leaving ary loxide. Thus. one nught suggest two different mechanisms to account for the result. i.e., a concerted mechanism and a stepwise pathway in which departure of the leaving group occurs in the RDS. However. one can exclude the latter mechanism since the leaving $\mathrm{Y}$-substituted phenoxides are less basic and better nucleofuges than the inconing $\mathrm{Ox}^{-}$. Accordingly. one can conclude that the current reactions proceed through a concerted mechanism.

Table 1. Sununary of Second-order Rate Constants for Reactions of Y-Substituted Phenyl Benzoates (1 a-i) with Butane-2,3-dione Monoximate $\left(\mathrm{Ox}^{-}\right)$and 4-Chlorophenoxide (4-C.PhO') in $80 \mathrm{~mol} \% \mathrm{H}_{2} \mathrm{O} / 20 \mathrm{~mol} \% \mathrm{DMSO}$ at $25.0 \pm 0.1^{\circ} \mathrm{C}$.

\begin{tabular}{|c|c|c|c|c|c|}
\hline & $Y$ & $\mathrm{p}_{\mathrm{a}}{ }^{\mathrm{S} \cdot \mathrm{Ph} \text { IIJ }}$ & $k_{0 \mathrm{x}}-\mathrm{M}^{-1} \mathrm{~s}^{-1}$ & $k_{\mathrm{A}-\mathrm{C} \mathrm{Ph} \mathrm{O}^{-}} / \mathrm{M}^{-1} \mathrm{~s}^{-1}$ & $k_{\mathrm{Ox}^{-}} / \mathrm{k}_{\mathrm{A} \text {-Cleho- }}$ \\
\hline 1a & 3-COMe & 10.4 & 0.703 & $3.45 \times 10^{-3}$ & 204 \\
\hline 1b & $3-\mathrm{CHO}$ & 10.1 & 1.22 & $6.10 \times 10^{-3}$ & 200 \\
\hline $1 c$ & $3-\mathrm{NO}_{2}$ & 9.32 & 9.78 & $4.16 \times 10^{-2}$ & 235 \\
\hline 1d & 4-COMe & 8.94 & 4.01 & $2.36 \times 10^{-2}$ & 170 \\
\hline $1 e$ & $4-\mathrm{CHO}$ & 8.45 & 8.39 & $5.52 \times 10^{-2}$ & 152 \\
\hline 1f & $4-\mathrm{NO}_{2}$ & 7.79 & 34.2 & $1.85 \times 10^{-1}$ & 185 \\
\hline $1 \mathrm{~g}$ & $4-\mathrm{Cl}-2-\mathrm{NO}_{2}$ & 6.92 & 47.1 & $2.15 \times 10^{-1}$ & 219 \\
\hline $1 \mathrm{~h}$ & $3,4-(\mathrm{NO} 2)_{2}$ & 5.60 & 961 & 7.19 & 134 \\
\hline $1 \mathbf{i}$ & $2,4-\left(\mathrm{NO}_{2}\right)_{2}$ & 4.11 & - & 6.50 & - \\
\hline
\end{tabular}

"The $\mathrm{p} \mathrm{K}_{\mathrm{a}}$ values in 20 molon DMSO and kinetic data for reactions with 4-ClPhO' were taken from ref. 20. 


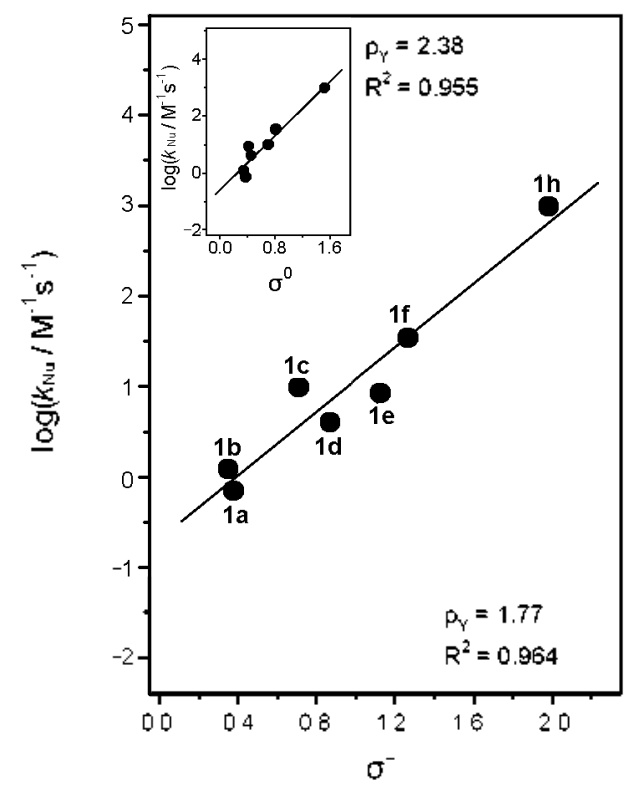

Figure 1. Hammett plots correlated with $\sigma^{-}$and $\sigma^{\prime \prime}$ (inset) for reactions of $\mathrm{Y}$-substituted phenyl benzoates ( $1 \mathrm{a}-\mathrm{h}$ ) with $\mathrm{Ox}^{-}$in $80 \mathrm{~mol} \% \mathrm{H}_{2} \mathrm{O} /$ $20 \mathrm{~mol} \% \mathrm{DMSO}$ at $25.0 \pm 0.1^{\circ} \mathrm{C}$. The identity of points is given in Table 1 .

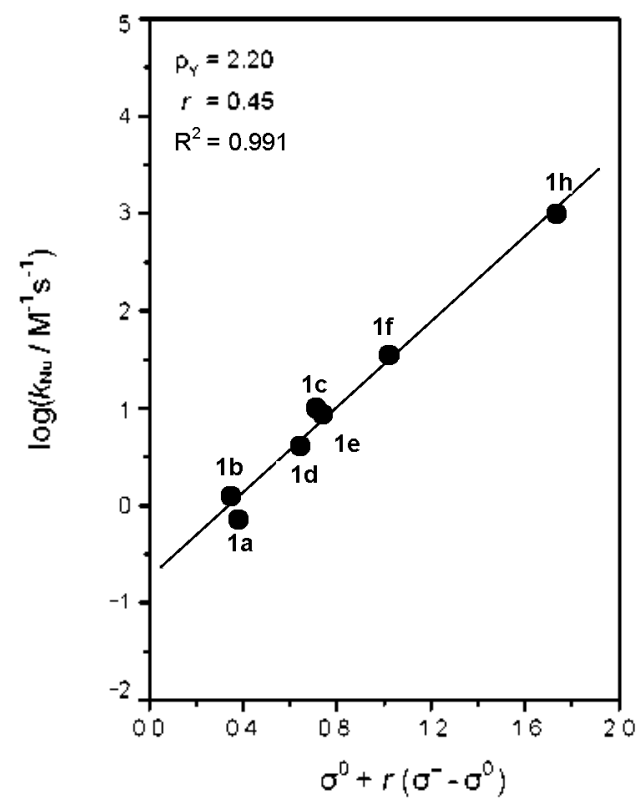

Figure 2. Yukawa-Tsuno plots for reactions of Y-substituted phenyl benzoates (1a-h) with $\mathrm{Ox}^{-}$in $80 \mathrm{~mol} \% \mathrm{H}_{2} \mathrm{O} / 20 \mathrm{~mol} \%$ DMSO at 25.0 $\pm 0.1^{\circ} \mathrm{C}$. The identity of points is given in Table $\mathrm{I}$.

$$
\log k^{\mathrm{r}^{\prime} / k^{\mathrm{H}}}=\rho_{\mathrm{Y}} \cdot\left(\sigma^{\mathrm{O}}+r\left(\sigma^{-}-\sigma^{\circ}\right)\right)
$$

Origin of the $\alpha$-Effect: GS Destabilization $v s$. TS Stabilization. As mentioned in the preceding section. $\mathrm{Ox}^{-}$is over $10^{-}$ times more reactive than its reference nucleophile. $4-\mathrm{ClPhO}^{-}$. although the basicity of the two nucleophiles is known to be similar (e.g. the $\mathrm{pK}_{\mathrm{a}}^{-}$values of the conjugate acids of $\mathrm{Ox}^{-}$and $4-\mathrm{ClPhO}^{-}$in $20 \mathrm{~mol} \% \mathrm{DMSO}$ were reported to be 10.68 and 10.58. respectively) ${ }^{16}$ Interestingly'. Table I shows that the mag-
Table 2. Summary of Second-order Rate Constants ( $k_{2}$-fho-) for Reactions of $Y$-Substituted Phenyl Benzoates $\left(\mathrm{Y}=4-\mathrm{NO}_{2}\right.$, lf: $\mathrm{Y}=4-\mathrm{Cl}-2$ $\left.\mathrm{NO}_{2}, 1 \mathrm{~g}: \mathrm{Y}=3,4-\left(\mathrm{NO}_{2}\right)_{2}, 1 \mathrm{~h} ; \mathrm{Y}=2,4-\left(\mathrm{NO}_{2}\right)_{2}, 1 \mathrm{i}\right)$ with Z-Substituted Phenoxides in $80 \mathrm{~mol} \% \mathrm{H}_{2} \mathrm{O} / 20 \mathrm{~mol} \%$ DMSO at $25.0 \pm 0.1{ }^{\circ} \mathrm{C}$ "

\begin{tabular}{clccccc}
\hline \multirow{2}{*}{ Entry } & \multirow{2}{*}{$Z$} & \multirow{2}{*}{$\mathrm{pK}_{\mathrm{a}}^{2-\mathrm{PhOH}}$} & \multicolumn{4}{c}{$10^{2} k_{\mathrm{Z}-\mathrm{PhO}} / \mathrm{M}^{-1} \mathrm{~s}^{-1}$} \\
\cline { 4 - 7 } & & 11.7 & 92.5 & 84.1 & 2080 & 2170 \\
\hline 1 & $4-\mathrm{Me}$ & $1 \mathrm{~h}$ & $1 \mathrm{~h}$ & $\mathbf{1 h}$ & $1 \mathrm{i}$ \\
2 & $\mathrm{H}$ & 11.3 & 45.2 & 35.5 & 1580 & 1160 \\
3 & $4-\mathrm{Cl}$ & 10.5 & 18.5 & 21.5 & 719 & 650 \\
4 & $3-\mathrm{Cl}$ & 10.2 & 9.03 & 11.2 & 424 & 397 \\
5 & $4-\mathrm{COMe}$ & 8.94 & 0.888 & 0.945 & 36.0 & 36.8 \\
6 & $4-\mathrm{CN}$ & 8.60 & 0.510 & 0.656 & 18.6 & 29.4 \\
\hline
\end{tabular}

${ }^{a}$ The $\mathrm{p}_{\mathrm{a}}$ values in $20 \mathrm{~mol}{ }^{\mathrm{d}}, \mathrm{DMSO}$ and kinetic data for the reactions of 4 -nitrophenyl benzoate ( $1 \mathrm{f})$ were taken from ref. 20 .

nitude of the $\alpha$-effect is independent of the electronic nature of the substituent $Y$ in the leaving group. This is in contrast to our previous report that the $\alpha$-effect increases linearly with increasing the basicity of the leaving group for reactions of Y-substituted phenyl benzoates with hydrazine (an $\alpha$-nucleophile) and glycylglycine (a reference nucleophile) ${ }^{26}$

Stabilization of transition state (TS) through intramolecular $\mathrm{H}$-bonding as modeled by 2 las been suggested to be responsible for the substituent dependent $\alpha$-effect for the reactions with hydrazine, since such 5-membered $\mathrm{H}$-bonding interaction is not possible for the corresponding reactions with glycylglycine ${ }^{26}$ One might draw a sinular conclusion that TS stabilization is responsible for the $\alpha$-effect shown by $\mathrm{Ox}^{-}$in the current study. This is because TS stabilization through intramolecular general acid/base catalysis as modeled by 3 is possible for the reactions with $\mathrm{Ox}^{-}$. while such general acid/base catalysis is impossible for the reactions with $4-\mathrm{ClPhO}^{-}$.

If TS stabilization through 3 is responsible for the enlanced reactivity shown by $\mathrm{Ox}^{-}$, the $\alpha$-effect should be dependent on the nature of the substituent $Y$ in the leaving group as reported previously for the reactions with hydrazine and glycylglycine. ${ }^{-6}$<smiles>[Y]c1cccc(OC2(OC)NNNC2NC)c1</smiles><smiles>[Y]c1cccc(OC(OC(=O)C(C)(C)C)(Oc2ccccc2)C(C)(C)C)c1</smiles>

However. in fact. the magnitude of the $\alpha$-effect is independent of the substituent $Y$ (see Table 1). indicating that TS stabilization through general acid/base cataly sis is not responsible for the $\alpha$ effect found in this study:

$\mathrm{Ox}^{-}$has been reported to be $5.7 \mathrm{kcal} / \mathrm{mol}$ less solvated than $4-\mathrm{ClPhO}^{-}$in $20 \mathrm{~mol} \% \mathrm{DMSO}^{1+\mathrm{th}}$ which is the reaction medium in this study. Since $\mathrm{Ox}^{-}$and $4-\mathrm{ClPhO}^{-}$have been employed as a pair of nucleophiles throughout the reactions of $\mathbf{1 a - i}$, the difference in the GS solvation energy of the two nucleophiles remains constant at $5.7 \mathrm{kcal} / \mathrm{mol}$. Accordingly. if the difference 

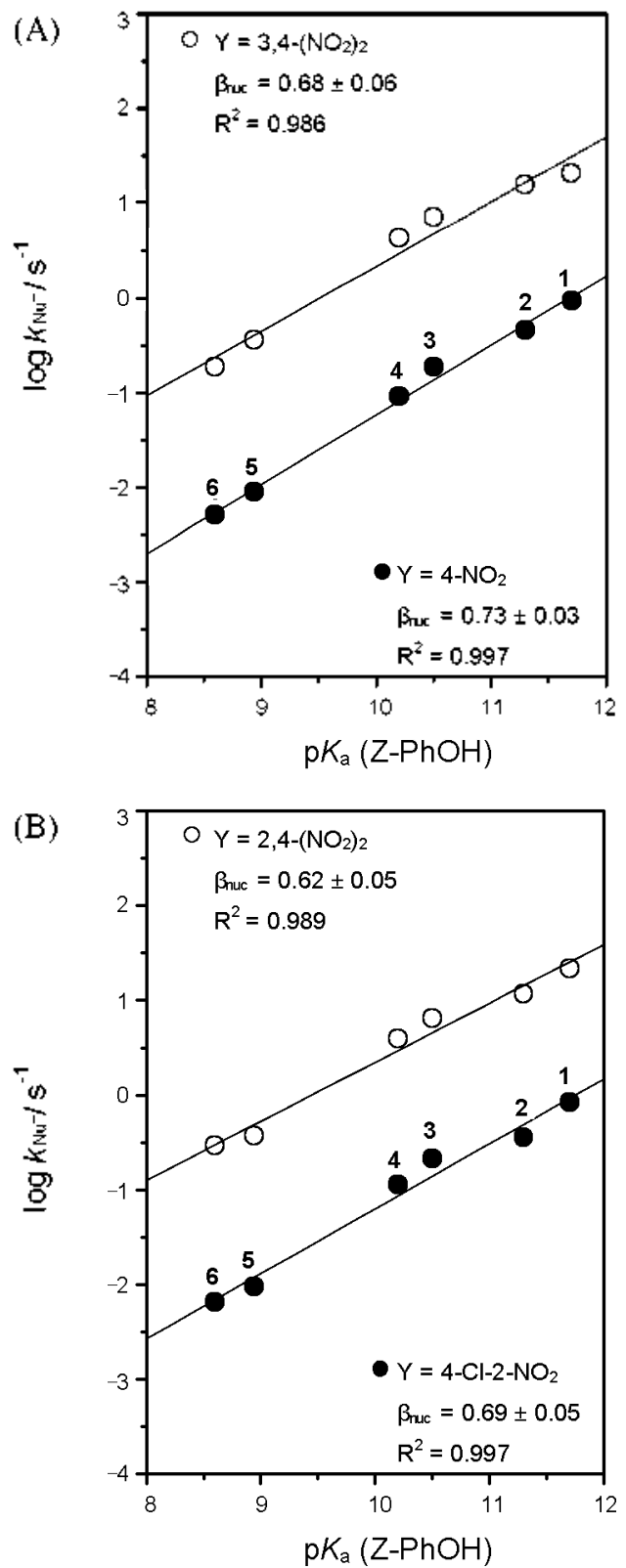

Figure 3. Bronsted-type plots for reactions of $Y$-substituted phenvl benzoates with $Z$-substituted phenoxies in $80 \mathrm{~mol} \% \mathrm{H}_{2} \mathrm{O} / 20 \mathrm{~mol} \%$ DMSO at $25.0 \pm 0.1^{\circ} \mathrm{C} \cdot \mathbf{A}: \mathrm{Y}=4-\mathrm{NO}_{2}(\mathbf{1 f})$ and $3,4-\left(\mathrm{NO}_{2}\right)$ (1h); $\mathrm{B}: \mathrm{Y}=$ $4-\mathrm{Cl}-2-\mathrm{NO}_{2}(1 \mathrm{~g})$ and $2,4-\left(\mathrm{NO}_{2}\right)_{2}$ (1i). The identity of points is given in Table 2 .

in the GS solvation energies of the two nucleophiles is mainly responsible for the $\alpha$-effect. one can expect that the magnitude of the $\alpha$-effect remains nearly constant upon changing the substituent $Y$ in the leaving group. In fact. the $\alpha$-effect is independent of the nature of $Y$. Thus. one can suggest that the $\alpha$-effect found in this study is mainly due to destabilization of $\mathrm{Ox}^{-}$in the GS.

To examine the above idea, second-order rate constants $\left(k z\right.$-Plu $\left.i^{-}\right)$have been measured for reactions of 4 different $Y$-substituted pheny 1 benzoates with 6 different $Z$-substituted phenoxides $\left(\mathrm{Z}-\mathrm{PhO}^{-}\right)$. The $\mathrm{kz}$-Pho- values are summarized in Table 2 and illustrated graphically in Figures $3 \mathrm{~A}$ and $3 \mathrm{~B}$. Table 2 shows that $k z$-pyri- decreases as the basicity of $Z \cdot \mathrm{PhO}^{-}$decreases in all cases. It is also noted that the $k_{z-\text {-Pho- }}$-values for the reactions of li are not always larger than those for the corresponding reactions of $\mathbf{1 h}$. although 2,4-dinitrophenoxide in $\mathbf{l i}$ is less basic than 3,4-dinitrophenoxide in $1 \mathrm{~h}$. Similarly, $1 \mathrm{~g}$ is not always nore reactive than 1f. although the former possesses a nuch less basic leaving group (i.e., 4-chloro-2-nitrophenoxide) than the latter does (i.e., 4-nitrophenoxide). One might suggest that steric hindrance caused by the substituent on the 2-position of $\mathrm{li}$ and $\mathrm{lg}$ is responsible for the unusual reactivity order. ${ }^{\text {? }}$

The effect of basicity of Z-PhO- on reactivity is illustrated in Figures $3 \mathrm{~A}$ and $3 \mathrm{~B}$. The Bronsted-type plots are linear with $\beta_{31 \mathrm{k}}$ values varying from 0.73 to 0.69 .0 .68 and 0.62 as the substituent $\mathrm{Y}$ changes from 4-NO 2 to 4-Cl-2-NO$, 3,4-\left(\mathrm{NO}_{2}\right)_{2}$, and 2.4$\left(\mathrm{NO}_{2}\right)_{2}$ in turn, which is in accordance to reactivity-selectivity principle. $^{28}$

It is well known that the magnitude of the $\alpha$-effect increases with increasing $\beta_{\text {nuc }}$ values when TS stabilization is responsible for the $\alpha$-effect. ${ }^{2,5.8}$ The $\beta_{\text {muc }}$ values deternined in this study exhibit a linear correlation with the basicity of the leaving Y-substituted phenoxides (Figure not shown). Thus. one nught expect that the $\alpha$-effect increases with increasing the leaving-group basicity, if TS stabilization (through general acid/base catalysis as modeled by 3 ) contributes to the current $\alpha$-effect. However. in fact, the $\alpha$-effect is independent of the leaving-group basicity. indicating that stabilization of TS is not responsible for the $\alpha$ effect. This is consistent with the preceding argument that the $\alpha$-effect found in current study is mainly due to GS destabilization.

\section{Conclusions}

The current study has allowed us to conclude the following: (1) The Yukawa-Tsuno plot for the reactions of Y-substituted phenyl benzoates (1a-h) with $\mathrm{Ox}^{-}$exhibits good linearity with $\rho_{\mathrm{Y}}=2.20$ and $r=0.45$, indicating that expulsion of the leaving group occurs in RDS. (2) A concerted mechanism or a stepwise pathway, in which expulsion of the leaving-group occurs in RDS, can account for the results. However. the latter mechanism has been excluded since $\mathrm{Y}$-substituted phenoxides are less basic and better nucleofuges than the inconing $\mathrm{Ox}^{-}$ion. (3) $\mathrm{Ox}^{-}$is over $10^{2}$ times more reactive than $4-\mathrm{ClPhO}^{-}$toward $\mathbf{l a t h}$ (i.e., the $\alpha$-effect). (4) TS stabilization through intramolecular general acid/base catalysis has been ruled out as the origin of the $\alpha$ effect found in the current reactions, since the magnitude of the $\alpha$-effect is independent of the nature of substituent $Y$ and of $\beta_{\mathrm{m} u \mathrm{c}}$ values. (5) Since Ox ${ }^{-}$has been reported to be $5.7 \mathrm{kcal} / \mathrm{mol}$ less solvated than $+-\mathrm{ClPhO}^{-}$in $20 \mathrm{~mol} \%$ DMSO. GS destabilization of $\mathrm{Ox}^{-}$has been concluded to be mainly responsible for the $\alpha$-effect found in this study.

\section{Experimental Section}

Materials. Y-Substituted phenyl benzoates were readily prepared from reactions of benzoyl chloride with $\mathrm{Y}$-substituted phenol in anhydrous ether under the presence of trietlylanine. The crude products were purified through column chromatography. Other chemicals including butane-2,3-dione monoxime 
and phenols were of the highest quality axailable. Doubly glassdistilled water was further boiled and cooled under nitrogen just before use to exclude dissolved $\mathrm{CO}_{2}$. Since solubility of the substrates is low in pure water. $80 \mathrm{~mol}^{2} \mathrm{H}_{2} \mathrm{O} / 20 \mathrm{~mol} \% \mathrm{DMSO}$ was used as the reaction medium.

Kinetics. The kinetic study was performed using a UV-Vis spectrophotometer for slow reactions $\left(t_{1:}>10 \mathrm{~s}\right)$ or a stoppedflow spectrophotometer for fast reactions $\left(t_{1: 2} \leq 10 \mathrm{~s}\right)$ equipped with a constant temperature circulating bath. The reactions were followed by monitoring the appearance of Y-substituted phenoxide at a fixed wavelength corresponding the maximum absorption.

Typically. the reaction was initiated by adding $5 \mu \mathrm{L}$ of a 0.02 $\mathrm{M}$ substrate stock solution in MeCN by a $10 \mu \mathrm{L}$ șringe to a 10 $\mathrm{mm}$ UV cell containing $2.50 \mathrm{~mL}$ of the reaction medium and nucleoplile. The nucleophile stock solution of $c a .0 .2 \mathrm{M}$ for the reactions was prepared in $25.0 \mathrm{~mL}$ volumetric flask under nitrogen by adding 2 equiv , of butan-2,3-dione monoxime (or $\mathrm{Z}$-substituted phenol) to I equiv. of standardized $\mathrm{NaOH}$ solution to obtain a self-buffered solution. Transfers of solutions were carried out by means of gas-tight syringes. All reactions were camied out under pseudo-first-order conditions in which nucleophile concentrations were at least 20 times geater than the substrate concentration.

Product Analysis. Y-substituted phenoxide (and/or it conjugate acid) was identified as one of the products by comparison of the UV-Vis spectra at the end of reactions with the authentic sample

Acknowledgments. The authors are grateful for the financial support from the Korea Research Foundation (KRF-2008-313C00500) and BK 21 Scholarship.

\section{References}

1. Edwards, J. O.; Pearson, R. G. J. Am. Chem. Soc. 1962, 84, 16-24.

2. Recent Reviews: (a) Buncel, E: Um, I. H. Tetrahedron 2004, 60, 7801-7825. (b) Buncel, E.: Unn, I. H.: Terrier, F. The Chemistr of Hydrowlamines, Oximes and Hytroxamic acids: Wiley Press: West Sussex, 2009; Chapter 17.

3. (a) Kirby, A. J: Tondo, D. W.; Medeiros, M.; Souza, B. S.: Priebe, I. P.: Lima, M. F.: Nome, F. J. Am. Chem. Soc. 2009, 131, 20232028. (b) Kirby, A. J.: Lima, M. F.: da Silva, D.; Roussev, C. D.: Nome, F. J. Ant. Chent. Soc. 2006, 129, 16944-16952 (c) Kirby, A. T.: Dutta-Rov, N : da Silva, D.; Goodman, I. M.: Lima, M. F.; Roussev, C. D.: Nome, F. J. Ant Chent Soc. 2005, 127, 7033-7040.

4. (a) Terrier, F.: Rodrigue $z$-Dafonte, P.: Le Guevel, E.: Moutiers, G. Org. Biomol. Chem. 2006, 1, 4352-4363. (b) Terrier, F.: Le Guevel, E.; Chatrousse, A. P.: Moutiers, G.; Buncel, E. Chent. Commun. 2003, 600-601. (c) Buncel, E.; Cannes, C.; Chatrousse, A. P.; Terier, F. J.Am. Chem. Soc. 2002, 124, 8766-8767. (d) Moutiers, G.; Le Guevel, E.; Cannes, C.: Terrier, F.; Buncel, E. Eur. J. Org. Chem. 2001, $17,3279-3284$

5. (a) Fountain, K. R. J. Phys. OFg. Chent 2005, 18, 481-485. (b) Fountain, K. R.: Felkerson, C. I.: Driskell, I. D.: Lamp. B. D. J. Org. Chem. 2003, 68, 1810-1814. (c) Fountain, K. R.; Tad-y, D. B.: Paul, T. W. Golynskiv, M. V.J. Ong Chem 1999, 64, 6547-6553.

6. (a) Tencks, W. P. Catatysis in Chemisty and Enzmologr; McGraw-Hill: New York, 1969: pp. 107-111. (b) Herschlag, D. Te- ncks, W. P. J.Am. Chem Soc. 1990,112, 1951-1956. (c) Jencks, W. P. Chem. Rev 1985, 85, 51 1-526. (d) Jencks, W. P.: Gilchrist, M. J. Am. Chem. Soc. 1968, 90, 2622-2637.

7. (a) Bemasconi, C. F.; Leyes, A. E.; Eventova, I.; Rappoport, $Z$. $J$. An. Chent Soc. 1995, 117, 1703-171 1. (b) Bemasconi, C. F.Ad Phws. Org. Chem 1992, 27, 119-238. (c) Bemasconi, C. F.; Stronach, M. W. J. Org. Chem 1991, 56, 1993-2001.

8. (a) Curci, R.; Di Furia, F. Int. J. Chem. Kinet 1975, 7, 341-349. (b) Gregory, M. T.; Bruice, T. C.J.Am. Chem. Soc. 1967,89, 44004405 .

9. Patterson, E. V.; Fountain, K. R. J. Org. Chem. 2006, 71, 81218125.

10. McAnoy, A. M.; Paine, M. R.; Blanksby, S. J. Org. Bionol. Chent. 2008, $6,2316-2326$

11. (a) Ren, Y.; Yamataka, H. J Comput. Chem 2009, 30, 358-365. (b) Ren, Y.: Yamataka, H. J. Org. Chem. 2007, 72, 5660-5667. (c) Ren, Y.; Yamataka, H. Chem. Eur. J. 2007, 13,677-682. (d) Ren, Y.; Yamataka, H. Ong. Lett. 2006, 8, $119-121$

12. Depuy, C. H.; Della, E. W,; Filley, J.: Grabowski, I. J.; Bierbaum, V. M J.tm. Chem. Soc 1983, 105, 2481-2482.

13. Villano, S. M:; Evet, N.; Lineberger, W. C.; Bierbaum, V. M. J. Ant. Chem. Soc. 2009, 131, 8227-8233.

14. (a) Buncel, E, Um, I. H. Chem. Commm 1986, 595-596. (b) Um, I. H.: Buncel, E. J. Org. Chem. 2000, 65, 577-582.

15. Um, I. H.; Hwang, S. J.; Buncel, E. J. Org. Chem 2006, 71,915920

16. Um, I. H.; Shin, Y. H.; Han, J. Y.; Buncel, E. Com. J. Chem. 2006, $84,1550-1556$

17. (a) Um, I. H.; Hong, I. Y.: Buncel, E. Chem Commm 2001, 27-28. (b) Tarkka, R. M.; Buncel, E. J.Am. Chem. Soc. 1995, 117, 15031507

18. (a) Um, I. H: Park, Y. M.: Buncel. E. Chem Commm 2000, $1917-$ 1918 (b) Um, I. H.: Lee, E. J:- Buncel, E. J Org Chem 2001, 66 , $4859-4864$

19. (a) Um, I. H.; Han, I. Y.; Buncel, E. Chem. Eur.J. 2009, 15, 101 l1017. (b) Um, I. H.: Buncel, E. J. Am. Chem. Soc. 2001, 123, $11111-11112$.

20. Im, L. R.; Um, I. H. Bull Korem Chem Soc 2009, 30, $2403-2407$.

21. (a) Um, I. H.; Mir, H. S.; Alu1, J. A; Hahn, H. J. J. Org. Chem. 2000, 65, 5659-5663. (b) Um, I. H.; Kim, K. H.; Park. H. R.; Fujio, M.; Tsuno Y.J. Org. Chem 2004, 69, 3937-3942

22. Um, I. H.: Hwang, S. J: Yoon, S. R., Jeon, S. E.: Bae, S. K. J. Org. Chem. 2008, 73, 7671-7677.

23. (a) Um, I. H.; Han, I. Y. Shin, Y. H. J. Org. Chent. 2009, 74 , 30733078 (b) Um, I. H.: Han, I. Y.; Hwang. S. T. Chem. Enr. J. 2008, 14, 7324-7330. (c) Um. I. H.: Alhtar. K.: Shin. Y. H.: Han. I. Y.J. Org. Chem. 2007, 72, 3823-3829. (d) Um, I. H.; Park, T. E.; Shin, Y. H. Org. Bionol. Chem. 2007, 5, 3539-3543.

24. (a) Tsuno, Y.: Fujio, M. Adv Phes Org Chem 1999, 32, 267-385. (b) Tsuno, Y.: Fujio, M. Chem. Soc.Rev 1996, 25, 129-139. (c) Yukawa, Y.; Tsuno, Y. Bull. Chem. Soc. Jph 1959, 32, 965-970.

25. (a) Than, S.; Maeda, H.: Irie, M.; Kikukawa, K.; Mishima, M. $h$ th. I. Wass. Spec 2007, 263, 205-214. (b) Maeda, H.; Irie, M.; Tharl, S.: Kikukawa, K.: Mishima, M. Bull. Chem. Soc. Jpn, 2007, 80, 195-203. (c) Mishima, M.; Maeda, H.: Than. S.: Irie, M.: Kikulkawa, K. J. Plys. Org. Chent 2006, 19,616-623. (d) Fujio, M: Alam, M. A.; Ume zaki, Y.; Kikukawa, K.; Fujiyama, R.; Tsuno, Y. Bull Chem. Soc. Jpn. 2007, 80, 2378-2383. (e) Fuijo, M.: Umezaki, Y.: Alam. M. A.: Kikukawa, K.: Fujiyama, R.; Tsuno, Y. Bull. Chem. Soc. Jpn. 2006, 79, 1091-1099.

26. Um. I. H.; Chung, E. K.; Lee, S. M. Con. J. Chent 1998, 76, 729. 737

27. (a) Seo, I. A.: Lee, H. M.: Um, I. H. Bull. Korean Chem. Soc. 2008. 29, $1915-1919$. (b) Seo, J. A.; Chun, S. M.: Um, I. H. Bull. Korean Chem. Soc 2008, 29, 1459-1463. (c) Um, I. H., Akhtar, K. Bull. Korem Chem. Soc. 2008, 29, 772-776.

28. Pross, A. Adv. Phus. Ong. Chem 1977, 14,69-132. 